\title{
A three-dimensional numerical simulation of cell behavior in a flow chamber based on fluid-solid interaction
}

\author{
Long Bai ${ }^{\mathrm{a}}$, Yuhong Cui ${ }^{\mathrm{a},}$, Yixia Zhang ${ }^{\mathrm{b}}$ and $\mathrm{Na} \mathrm{Zhao}^{\mathrm{a}}$ \\ ${ }^{a}$ Department of Mechanics, Tianjin University, Tianjin, China \\ ${ }^{b}$ School of Engineering and Information Technology, UNSW Canberra, Canberra, Australia
}

\begin{abstract}
The mechanical behavior of blood cells in the vessels has a close relationship with the physical characteristics of the blood and the cells. In this paper, a numerical simulation method was proposed to understand a single-blood cell's behavior in the vessels based on fluid-solid interaction method, which was conducted under adaptive time step and fixed time step, respectively. The main programme was $\mathrm{C}++$ codes, which called FLUENT and ANSYS software, and UDF and APDL acted as a messenger to connect FLUENT and ANSYS for exchanging data. The computing results show: (1) the blood cell moved towards the bottom of the flow chamber in the beginning due to the influence of gravity, then it began to jump up when reached a certain height rather than touching the bottom. It could move downwards again after jump up, the blood cell could keep this way of moving like dancing continuously in the vessels; (2) the blood cell was rolling and deforming all the time; the rotation had oscillatory changes and the deformation became conspicuously when the blood cell was dancing. This new simulation method and results can be widely used in the researches of cytology, blood, cells, etc.
\end{abstract}

Keywords: Fluid-solid interaction, numerical simulation, jumping; rolling, deformation

\section{Introduction}

The blood cells living in the vessels are constantly subjected to all kinds of mechanical stimuli in vivo and in vitro. The blood cells' behavior will change as a response. For example, the white blood cells change their cytoskeleton after receiving the stimuli caused by chemokines, and then do amoeboid locomotion [1,2].

In recent years, some researchers are engaged in the tremendously complex problem of cell dynamics and its key role in numerous vital processes, such as cell migration [3], immunological processes, or the engulfment of bacteria [4,5]. Physicists have carried out many experimental and theoretical studies to reveal the relationship between the blood cells' behavior and the properties of blood [6,7]. A two-dimensional flexible-particle model was used by Jared O Barber, et al. to simulate the red blood cells' movement, deformation, and partitioning in microvessel bifurcations [8]. The model described the motion of a cell in a surrounding Stokes flow as it moved in a rigid vessel. The

\footnotetext{
${ }^{*}$ Corresponding author: Yuhong Cui, Department of Mechanics, Tianjin University, Tianjin, China. Tel.: +86-22-27404934; Fax: +86-22-27403754; E-mail: yhcui@tju.edu.cn.
} 
constraint of constant cell volume was represented by an effective internal pressure. This simulation considered motion of isolated cells and ignored cell-to-cell interactions [8-11]. Besides, Lattice Boltzmann Method is widely used to simulate cell behavior in shear flow $[12,13]$. The cell membrane was treated as a neo-Hookean viscoelastic material and a Morse potential was adopted to model the intercellular interaction [13].

Fluid-solid interaction (FSI) is the interaction of some movable or deformable solid with an internal or surrounding fluid flow. Research in the fields of computational fluid dynamics and computational solid dynamics is still ongoing but the maturity of these fields enables numerical simulation of fluid-solid interaction [14]. In this study, the blood cell moved and deformed under the influence of the fluid parameters. In the meantime, the movement and deformation of the blood cell in turn affected the flow field; furthermore the fluid parameters were changed, and so on.

This paper presented a new method to simulate a single-blood cell's behavior in a flow chamber based on FSI method. This study treated the cell membrane as linear elastic solid and ignored cell-to-cell interactions.

\section{Materials and methods}

\subsection{Methods}

Visual C++6.0, GAMBIT2.3.16, FLUENT6.3.26 and ANSYS12.0 were used in this threedimensional numerical simulation. GAMBIT was used to create computational fluid dynamics model and divide the grids. FLUENT was used to calculate the blood cell's displacement and rotation. ANSYS was used to calculate the blood cell's deformation. UDF and APDL acted as a messenger to connect FLUENT and ANSYS for exchanging data. More important is that Visual $\mathrm{C}++$ program was the main code controlling the above numerical simulation, which made by our team.

\subsection{Equations}

The mass conservation equation and momentum conservation equation were solved in the calculation, listed as Eqs. (1) and (2), respectively.

$$
\begin{aligned}
& \frac{\partial \rho}{\partial t}+\nabla \cdot(\rho \vec{v})=S_{m} \\
& \frac{\partial}{\partial t}(\rho \vec{v} \vec{v})=-\nabla p+\nabla \cdot(\bar{\tau})+\rho \vec{g}+\vec{F}
\end{aligned}
$$

The source $S_{m}$ is the mass added to the continuous phase from the dispersed phase, $p$ is the static pressure. $\bar{\tau}, \rho \vec{g}$ and $\vec{F}$ are the stress tensor, the gravitational body force and external body forces, respectively.

With respect to dynamic meshes, the integral form of the conservation equation for a general scalar $\phi$, on an arbitrary control volume. $V$, whose boundary is moving can be written as Eq. (3). 


$$
\frac{d}{d t} \int_{v} \rho \phi d V+\int_{\partial v} \rho \phi\left(\vec{u}-\vec{u}_{g}\right) \cdot d \vec{A}=\int_{\partial v} \Gamma \nabla \phi \cdot d \vec{A}+\int_{v} S_{\phi} d V
$$

Where $\rho$ is the fluid density, $\vec{u}$ is the flow velocity vector, $\vec{u}_{g}$ is the mesh velocity of the moving mesh, $\Gamma$ is the diffusion coefficient, $S_{\phi}$ is the source term of $\phi$. (4).

The equilibrium equation was the governing equation of the blood cell, which can be written as Eq.

$$
\nabla \cdot \sigma_{i j, j}+f_{i}=0
$$

Where $\sigma_{i j}$ is the normal stress when $i$ is equal to $j$ or the shear stress when $i$ is not equal to $j, f_{i}$ is the external force.

The constitutive equation for isotropic materials is as Eq. (5).

$$
\sigma_{i j}=\frac{E}{1+\gamma} E_{i j}+\frac{\gamma E}{(1+\gamma)(1-2 \gamma)} \theta \delta_{i j}
$$

Where $\sigma_{i j}$ is the stress, $\delta_{i j}$ is the strain, $\theta$ is the first strain invariant, $\mathrm{E}$ is the Modulus of elasticity, $\gamma$ is the Poisson's ratio.

\subsection{Computing model and computing procedure}

Figure 1 showed the model adopted in this numerical simulation. The flow chamber's length, width, and height were $200 \mu \mathrm{m}, 100 \mu \mathrm{m}$, and $50 \mu \mathrm{m}$. And the blood cell was a sphere with a diameter of $6 \mu \mathrm{m}$. The distances from the center of the blood cell to the bottom, the left side and the inlet of the flow chamber were $8.30 \mu \mathrm{m}, 83.30 \mu \mathrm{m}$ and $50 \mu \mathrm{m}$.

The grids of the flow chamber and the surface of the blood cell were divided in GAMBIT, and then ANSYS ICEM CFD divided the body mesh of the blood cell based on the surface mesh. The number of the surface meshes of the blood cell was 262 and the number of the volume meshes of the flow chamber was 1633394. The element of SOLID45 in ANYSY was chosen as the blood cell, which was considered structural, linear elastic and isotropic, the number of the elements was 1729.

Velocity inlet and free outlet were adopted as the type of the inlet and the outlet of the fluid field. The side face near the blood cell was wall and the other side face was symmetry. The fluid in the flow chamber was assumed to be blood. And the values of the parameters of the blood cell were set according to the properties of real cells. Table 1 showed the values of the parameters adopted in this numerical simulation. The velocity of the blood was in the positive direction of axis $\mathrm{x}$, and the acceleration of gravity was in the positive direction of axis $\mathrm{z}$. 


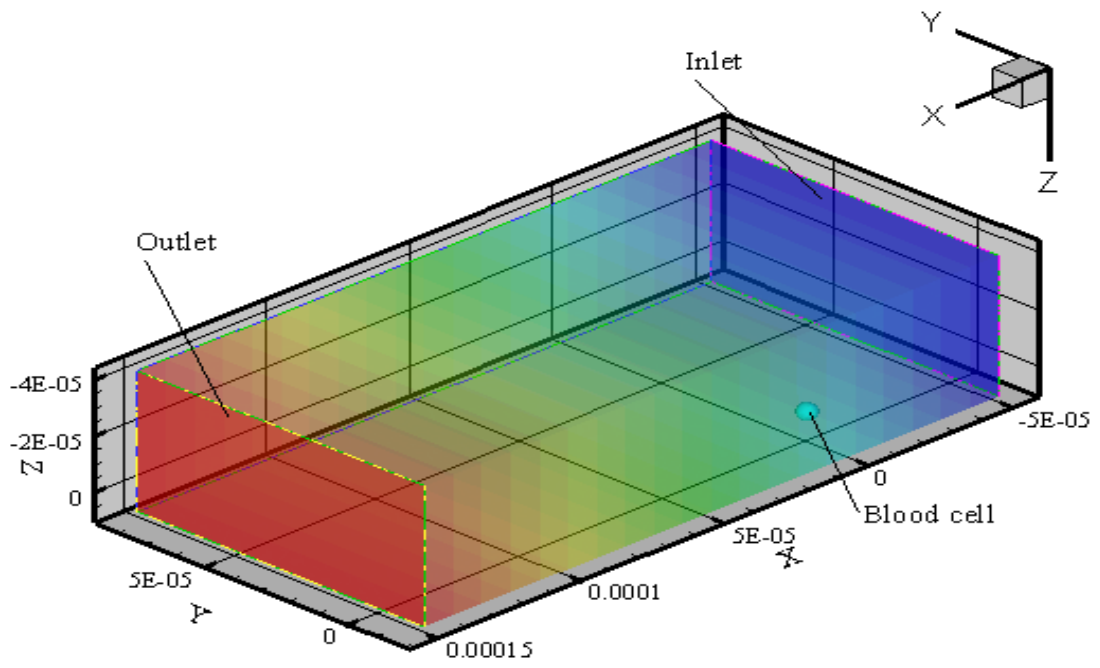

Fig. 1. Model adopted in the simulation.

Table 1

Parameters adopted in the simulation

\begin{tabular}{llll}
\hline Parameters & Value & Parameters & Value \\
\hline Density of the fluid $\left(\mathrm{kg} / \mathrm{m}^{3}\right)$ & 993.43 & Density of the blood cell $\left(\mathrm{kg} / \mathrm{m}^{3}\right)$ & 1099.94 \\
Viscosity of the fluid $(\mathrm{Pa} \cdot \mathrm{S})$ & $6.94 \mathrm{e}-4$ & Modulus of elasticity of the blood cell $(\mathrm{Pa})$ & 10000 \\
Inlet Velocity $(\mathrm{m} / \mathrm{s})$ & $6.67 \mathrm{e}-3$ & Poisson's ratio of the blood cell & 0.30 \\
Acceleration of gravity $\left(\mathrm{m} / \mathrm{s}^{2}\right)$ & 9.80 & The type of the elements of the blood cell & SOLID45 \\
\hline
\end{tabular}

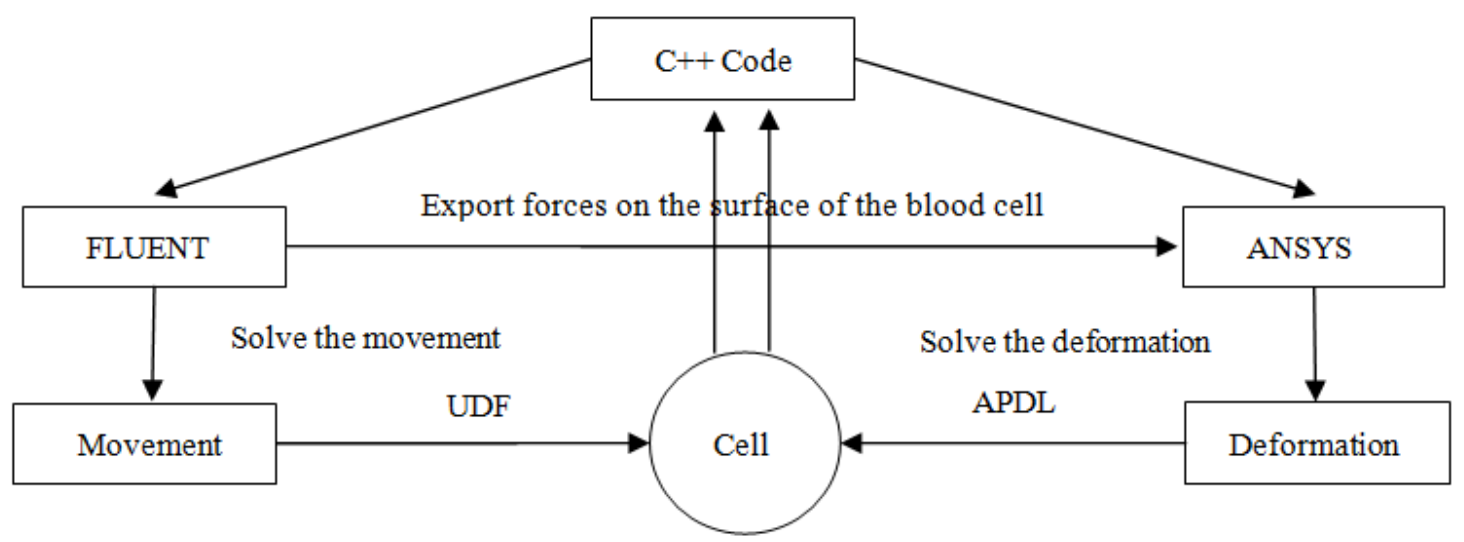

Fig. 2. Process of computation in one time step.

Reynolds number was 0.57 , so the flow was treated as laminar. This flow field was solved with a pressure-based finite volume method (FVM). The second upwind scheme and whole processing implicit iteration way were used. Solid field was analyzed by wave front method; double precision was 
selected at the same time. UDF defined in FLUENT and APDL language defined in ANSYS were used to program code for exchanging data between FLUENT and ANSYS.

Firstly, C++ code called FLUNET. FLUENT computed the flow parameters, and then exported the forces on the surface of the blood cell. UDF calculated the resultant force and resultant moment on the center of the blood cell, and then calculated the displacement and rotation of the blood cell. Secondly, UDF passed the forces, displacement and rotation of the blood cell to $\mathrm{C}++$ code. Thirdly, $\mathrm{C}++$ code called ANSYS to calculate the deformation of the blood cell, and then ADPL passed the deformation of the blood cell to $\mathrm{C}++$ code. Finally, the new position of the blood cell was updated. The whole computing procedure was completed once in every time step. Figure 2 showed the process of computation in one time step.

\subsection{Validation}

Since there are no available results for theoretical verification of the fluid-solid interaction, a horizontal projectile motion of the blood cell was simulated to verify the accuracy of the computation procedure. The validation model was exactly the same as the computing model, while the fluid in the flow chamber was changed to air with the same velocity, which could be approximated as a falling. If air resistance effect was ignored in this situation, the theoretical values of the velocity and displacement in the falling direction should satisfy Newton's second law, and the theoretical values of the velocity in the $x$ direction could assume to be stable. In the light of the numerical computing, the maximum errors of the blood cell's velocity and displacement in the $\mathrm{x}$ direction were both less than $0.20 \%$. The maximum error of the falling velocity was less than $0.30 \%$ and the maximum error of the falling displacement was less than $1 \%$. Thus, this simulation accuracy can be regarded as reliable due to air resistance assumed as the major cause.

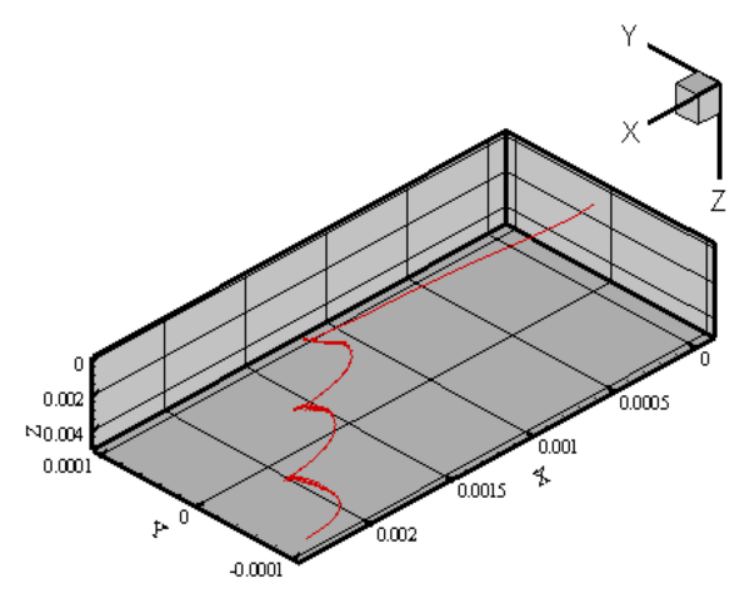

(a)

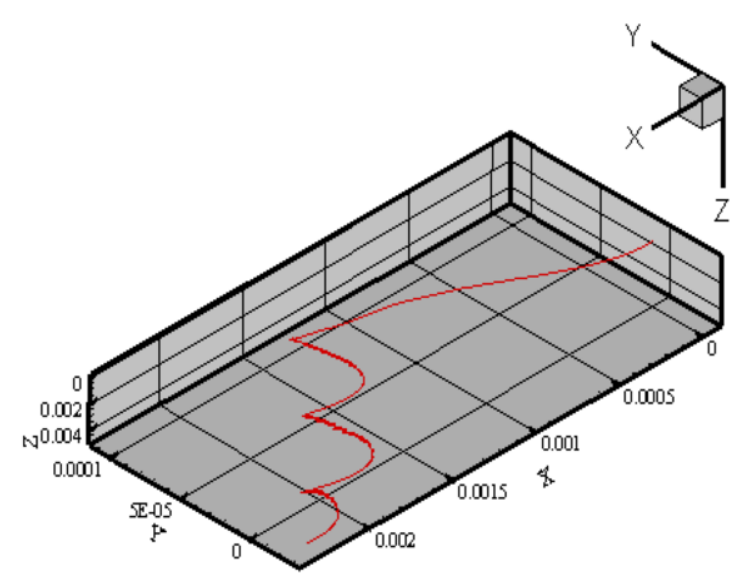

(b)

Fig. 3. Trajectory of the blood cell in the flow chamber. (a) Under adaptive time step (ATS); (b) Under fixed time step (FTS). 


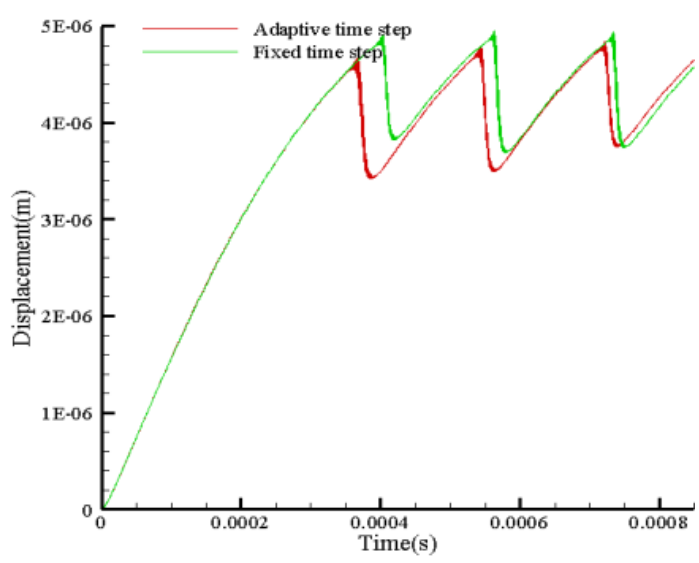

(a)

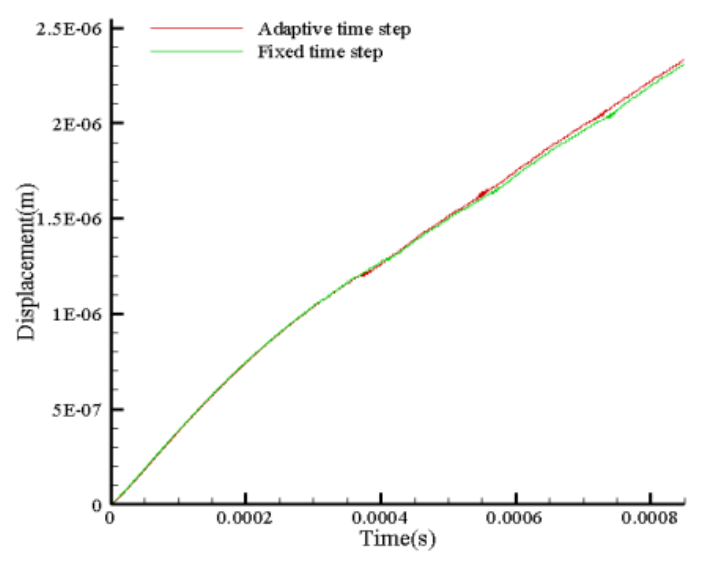

(b)

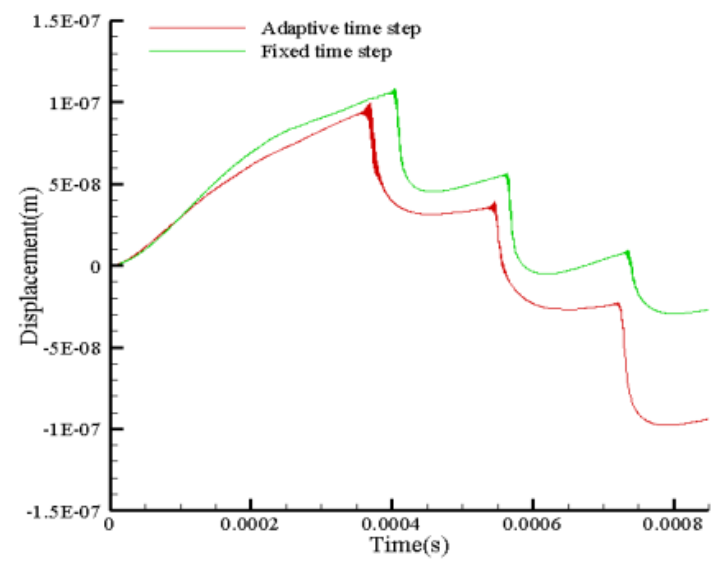

(c)

Fig. 4. Displacements of the blood cell in three directions. (a) Displacement in the $\mathrm{z}$ direction; (b) Displacement in the $\mathrm{x}$ direction; (c) Displacement in the y direction.

\section{Results}

This numerical simulation was conducted under adaptive time step (ATS) and fixed time step (FTS) which $5 \mathrm{e}-7 \mathrm{~s}$ was adopted, respectively. Figure 3 showed the three-dimensional picture of the blood cell's trajectory in the flow chamber. The blood cell moved towards the bottom of the flow chamber in the beginning rather than touching the bottom, and moved downwards again when raised to some height. At last it would keep the way of moving like dancing continuously in a spiral route.

Figure 4 showed the blood cell's displacements in three directions under adaptive time step (ATS) and fixed time step (FTS), respectively. The detailed data was shown in Table 2. The blood cell moved towards the bottom of the flow chamber at first and then began to jump up after 3.71e-4 s (ATS) and 4.01e-4 s (FTS). The distances from the center of the blood cell to the bottom of the flow chamber were $3.63 \mu \mathrm{m}$ (ATS) and $3.39 \mu \mathrm{m}$ (FTS). The blood cell raised a distance of $1.25 \mu \mathrm{m}$ (ATS) and 1.09 $\mu \mathrm{m}$ (FTS) within 1.02e-5 s (ATS) and 2.01e-5 s (FTS). Then the blood cell began to fall again and repeated this cyclic process which was basically the identical movement. 


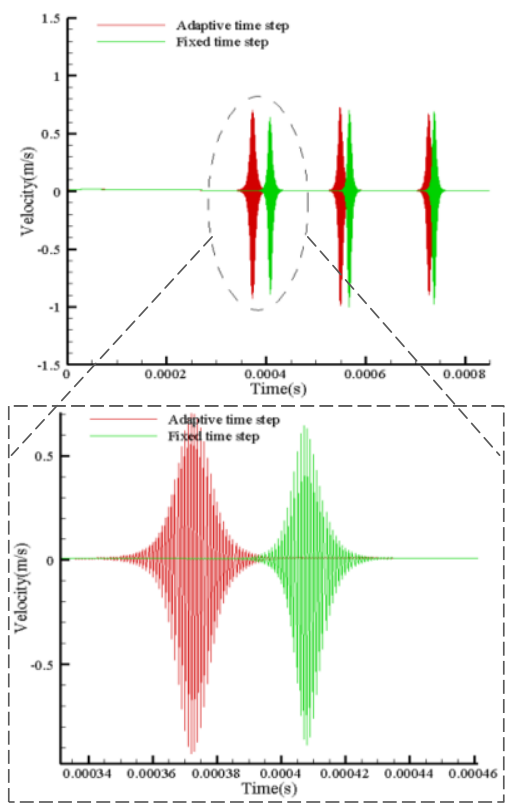

(a)

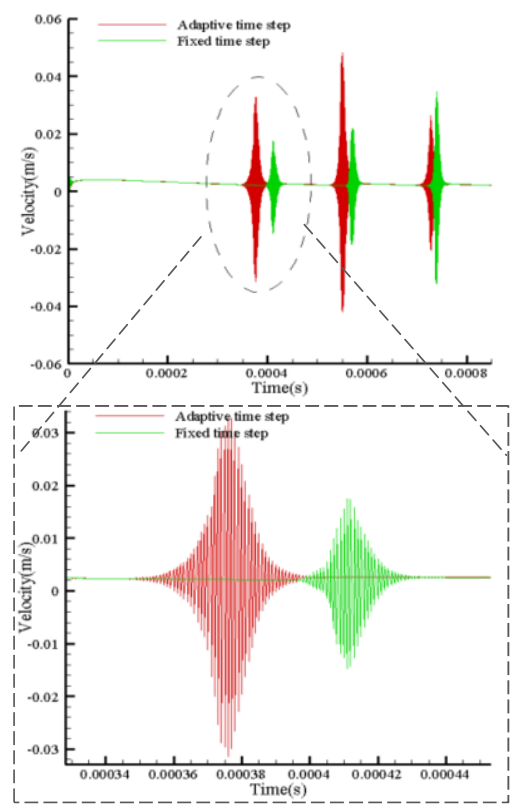

(b)

Fig. 5. Velocities of the blood cell in the $\mathrm{z}$ and $\mathrm{x}$ directions. (a) Velocity in the $\mathrm{z}$ direction; (b) Velocity in the $\mathrm{x}$ direction.

The displacement in the $\mathrm{x}$ direction was basically linear increment and there were no big changes in the whole process. The blood cell moved $1.75 \mu \mathrm{m}$ (ATS) and $1.73 \mu \mathrm{m}$ (FTS) in the $\mathrm{x}$ direction after $6.00 \mathrm{e}-4 \mathrm{~s}$ which was less than the displacement of the fluid $4.00 \mu \mathrm{m}$. The blood cell's movement in the $\mathrm{y}$ direction was complicated. The blood cell moved towards the positive of the $\mathrm{y}$ direction in the beginning, and moved a distance of 9.90e-2 $\mu \mathrm{m}$ (ATS) and 1.07e-1 $\mu \mathrm{m}$ (FTS) after 3.71e-4 s (ATS) and $3.99 \mathrm{e}-4 \mathrm{~s}$ (FTS). Then the blood cell turned to the negative position suddenly. The blood cell moved a distance of $6.75 \mathrm{e}-2 \mu \mathrm{m}$ (ATS) and $6.15 \mathrm{e}-2 \mu \mathrm{m}$ (FTS) in $8.01 \mathrm{e}-5 \mathrm{~s}$ (ATS) and $6.10 \mathrm{e}-5 \mathrm{~s}$ (FTS), and then turned back to the positive of the y direction again. The blood cell moved smoothly and advanced 7.70e-3 $\mu \mathrm{m}$ (ATS) and 1.04e-3 $\mu \mathrm{m}$ (FTS) within 9.02e-5 s (ATS) and 1.00e-4 s (FTS). The two-steering process took about 1.70e-4 s (ATS) and 1.61e-4 s (FTS). Then the blood cell would have another two-steering process in the next 1.70e-4 s approximately. Finally, the blood cell would repeat this cyclic process.

Figure 5 showed the blood cell's velocities in the $\mathrm{z}$ and $\mathrm{x}$ directions under adaptive time step (ATS) and fixed time step (FTS), respectively. The changing characteristics of the velocities were consistent with the displacements. In the $\mathrm{x}$ direction, the blood cell began to accelerate after a short time's oscillatory motion. The velocities reached $4.05 \mathrm{e}-3 \mathrm{~m} / \mathrm{s}$ (ATS) and $4.01 \mathrm{e}-3 \mathrm{~m} / \mathrm{s}$ (FTS) after $5.94 \mathrm{e}-5 \mathrm{~s}$ (ATS) and 7.40e-5 s (FTS). Then it began to decelerate. The velocities became $1.11 \mathrm{e}-3 \mathrm{~m} / \mathrm{s}$ (ATS) and $1.14 \mathrm{e}-3 \mathrm{~m} / \mathrm{s}$ (FTS) before the blood cell jumped. In the $\mathrm{z}$ direction, the acceleration of blood cell lasted for about $4.5 \mathrm{e}-5 \mathrm{~s}$ (ATS) and $4.3 \mathrm{e}-5 \mathrm{~s}$ (FTS) and the velocities reached $1.68 \mathrm{e}-2 \mathrm{~m} / \mathrm{s}$ (ATS) and 1.67e-2 $\mathrm{m} / \mathrm{s}$ (FTS). Then the blood cell began to decelerate. And the velocities became $1.44 \mathrm{e}-3 \mathrm{~m} / \mathrm{s}$ (ATS) and $1.50 \mathrm{e}-3 \mathrm{~m} / \mathrm{s}$ (FTS) before the blood cell jumped. During the blood cell's first dancing, the maximum velocities in the $z$ direction were $9.30 \mathrm{e}-1 \mathrm{~m} / \mathrm{s}$ (ATS) and $8.92 \mathrm{e}-1 \mathrm{~m} / \mathrm{s}$ (FTS) towards the negative direction, and the maximum velocities in the $x$ direction were $3.28 \mathrm{e}-2 \mathrm{~m} / \mathrm{s}$ (ATS) and $1.73 \mathrm{e}-2 \mathrm{~m} / \mathrm{s}$ (FTS) towards the positive direction. 
Table 2

Time and coordinate of the center of the blood cell while jumping

\begin{tabular}{|c|c|c|c|c|c|c|}
\hline Parameters & $\begin{array}{l}\text { Adaptive time step } \\
\text { (ATS) }\end{array}$ & $\begin{array}{l}\text { Fixed time step } \\
\text { (FTS) }\end{array}$ & Parameters & $\begin{array}{l}\text { Adaptive time } \\
\text { (ATS) }\end{array}$ & $\begin{array}{l}\text { step Fixed time } \\
\text { (FTS) }\end{array}$ & step \\
\hline 1st-jump time & $3.71 \mathrm{e}-4 \mathrm{~s}$ & $4.01 \mathrm{e}-4 \mathrm{~s}$ & 1st-fall time & $3.81 \mathrm{e}-4 \mathrm{~s}$ & $4.21 \mathrm{e}-4 \mathrm{~s}$ & \\
\hline Coordinate & $4.67 \mu \mathrm{m}$ & $4.91 \mu \mathrm{m}$ & Coordinate & $3.42 \mu \mathrm{m}$ & $3.82 \mu \mathrm{m}$ & \\
\hline $\begin{array}{l}\text { 2nd-jump } \\
\text { time }\end{array}$ & $5.40 \mathrm{e}-4 \mathrm{~s}$ & $5.58 \mathrm{e}-4 \mathrm{~s}$ & $\begin{array}{l}\text { 2nd-fall } \\
\text { time }\end{array}$ & $5.60 \mathrm{e}-4 \mathrm{~s}$ & $5.80 \mathrm{e}-4 \mathrm{~s}$ & \\
\hline Coordinate & $4.79 \mu \mathrm{m}$ & $4.95 \mu \mathrm{m}$ & Coordinate & $3.50 \mu \mathrm{m}$ & $3.69 \mu \mathrm{m}$ & \\
\hline 3rd-jump time & $7.20 \mathrm{e}-4 \mathrm{~s}$ & $7.30 \mathrm{e}-4 \mathrm{~s}$ & 3rd-fall time & $7.40 \mathrm{e}-4 \mathrm{~s}$ & $7.50 \mathrm{e}-4 \mathrm{~s}$ & \\
\hline Coordinate & $4.84 \mu \mathrm{m}$ & $4.94 \mu \mathrm{m}$ & Coordinate & $3.75 \mu \mathrm{m}$ & $3.74 \mu \mathrm{m}$ & \\
\hline
\end{tabular}

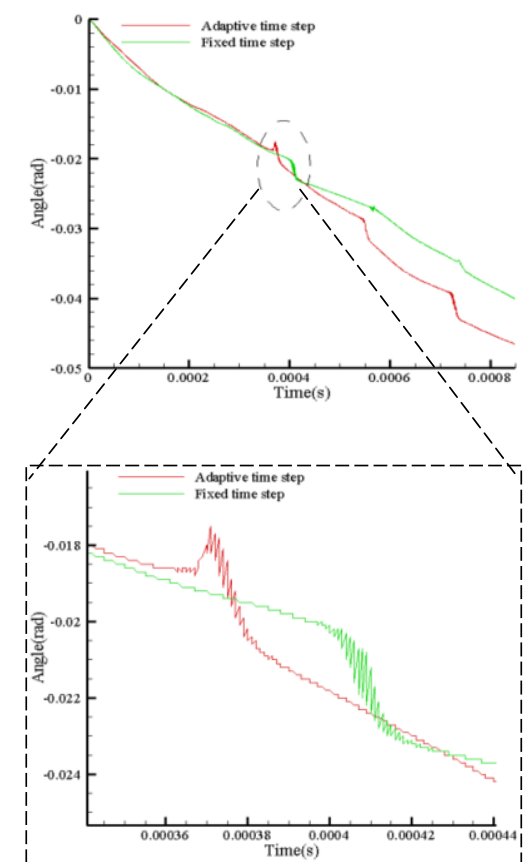

(a)

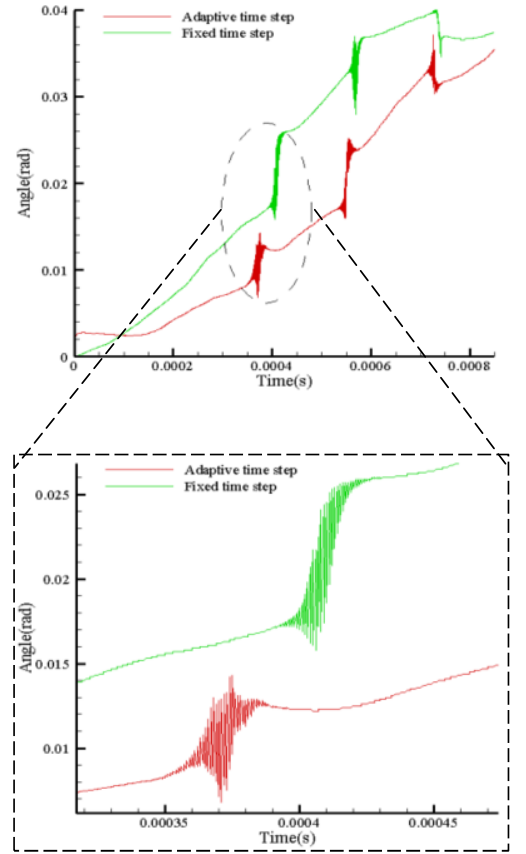

(b)

Fig. 6. Angles of rotation in the $\mathrm{z}$ and $\mathrm{x}$ directions. (a) Angle of rotation in the $\mathrm{z}$ direction; (b) Angle of rotation in the $\mathrm{x}$ direction.

The blood cell was not only moving but also rolling at the same time. The blood cell's angles of rotation in the $\mathrm{z}$ and $\mathrm{x}$ directions under adaptive time step (ATS) and fixed time step (FTS) were shown in Figure 6. The changes of the angles of rotation were in accordance with the displacements in every jump cycle.

The angle of rotation increased smoothly in the positive of the $\mathrm{x}$ direction before the blood cell's first jump. The blood cell rotated 1.28e-2 rad (ATS) and 1.70e-2 rad (FTS) after 3.71e-4 s (ATS) and 4.01e-4 s (FTS). Then oscillatory changes happened and lasted for about 3.70e-5 s (ATS) and 3.30e-5 $\mathrm{s}$ (FTS). In the $\mathrm{z}$ direction, the angle of rotation increased smoothly in the negative direction before the 
blood cell jumped. The blood cell rotated -1.82 rad (ATS) and -2.03 rad (FTS) after 3.71e-4 s (ATS) and $4.01 \mathrm{e}-4 \mathrm{~s}$ (FTS). Then the oscillatory changes happened although relatively smaller than the changes of the $x$ direction. This oscillatory motion lasted for about $1.49 \mathrm{e}-5 \mathrm{~s}$ (ATS) and 2.05e-5 s (FTS). Then the blood cell would repeat this cyclic process.

Deformation occurred in the whole process. The elastic strain of the blood cell at $3.71 \mathrm{e}-4 \mathrm{~s}$ was shown in Figure 7(a) and the stress on the surface of the blood cell at 3.71e-4 s was shown in Figure 7 (b) when the blood cell was jumping. The maximum deformation was $28.80 \%$ of the radius of the blood cell. Deformation determined largely by stress. The stress on the surface of the blood cell had drastic oscillatory changes when the blood cell was dancing. Moreover, the deformation files exported by ANSYS showed the deformation of the blood cell was more conspicuous when the blood cell was dancing.

\section{Discussion}

The blood cell was under the influence of drag force and lift force when moving in the flow chamber. The resultant force from the flow field in the z direction couldn't resist the influence of the gravity in the beginning because of the small pressure difference the blood cell subjected to and its small velocity. So the blood cell moved towards the bottom of the flow chamber.

In the meantime, the blood cell moved along the flow direction due to drag force. Moreover, the blood cell was rolling and deforming under the influence of drag force and lift force. The resultant force and the velocities in the $\mathrm{x}$ direction had oscillatory changes when the blood cell was dancing. Because the drag force and lift force were interacted with the velocities. Besides, deformation changed the contact surface between the blood cell and the fluid which could impact on the lift force and drag force. Therefore, the rotation had oscillatory changes and the deformation became conspicuously when the blood cell was dancing.

The blood cell moved and deformed under the influence of the fluid parameters. In the meantime, the movement and deformation in turn affected the flow field, thus changed the distribution and the size of the fluid parameters. The fluid interacted with the solid one step by step.

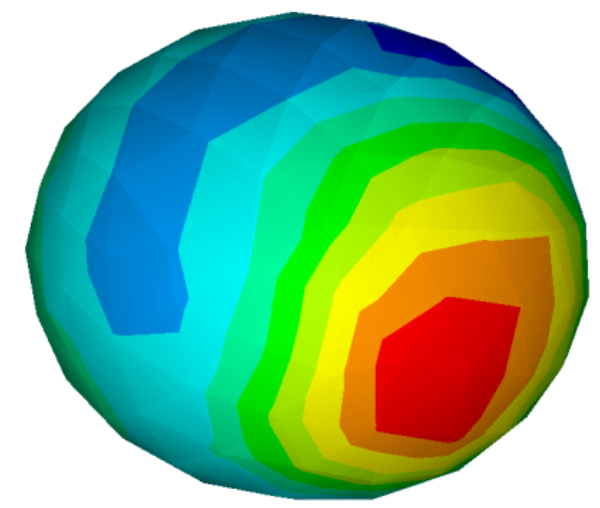

(a)

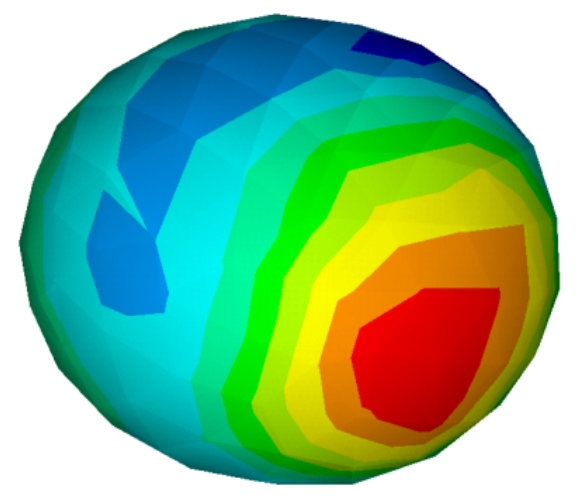

(b)

Fig. 7. Elastic strain and stress at 3.71e-4 s. (a) Elastic strain of the blood cell; (b) Stress of the blood cell. 


\section{Conclusion}

In this study, a three-dimensional numerical simulation method was proposed based on fluid-solid interaction method to discuss the mechanic behavior of the blood cell in a flow chamber. The motion and deformation of the blood cell were simulated simultaneously, which is different from the previous work. The results showed the blood cell moved along the direction of the flow field under the effect of drag force, in the meantime it moved towards the bottom of the flow chamber due to the influence of gravity, lift force and drag force. The blood cell jumped when reached a certain height rather than touching the bottom, but it would move downwards again after a period of rising. Finally, it would repeat this cyclic process like dancing. Moreover, the blood cell was rolling and deforming simultaneously. The rotation had oscillatory changes and the deformation became more conspicuous when the blood cell was dancing. The blood cell moved and deformed under the influence of the fluid parameters. Also, the movement and deformation in turn affected the flow field, thus changed the distribution and the size of the fluid parameters. The fluid interacted with the solid one step by step.

This study presented a new method to explore the blood cell's behavior in the vessels and provided application basis for clinical medicine. Besides, this method which is improvable can be applied to a lot of other related numerical simulations. Nevertheless, cell-to-cell interactions and the special mechanical properties of blood cells should be considered which will be studied in the future work.

\section{Acknowledgement}

This work was supported by the national natural science foundation of China (11172207 and 11272366). It is also sponsored by key laboratory of biorheological science and technology of Ministry of Education (CQKLBST-2012-002) and Tianjin research program of application foundation and advanced technology (11JCYBJC09700).

\section{References}

[1] P.Y. Jay, C. Pasternak and E.L. Elson, Studies of mechanical aspects of amoeboid locomotion, Blood Cells 19 (1993), 375-386.

[2] E.L. Elson, S.F. Felder, P.Y. Jay, M. S. Kolodney and C. Pasternak, Forces in cell locomotion, Biochemical Society Symposium 65 (1999), 299-314.

[3] A. Chauviere, L. Preziosi and H. Byrne, A model of cell migration within the extracellular matrix based on a phenotypic switching mechanism, Mathematical Medicine and Biology 27 (2009), 255-281.

[4] A. Hochreiter-Hufford, K.S. Ravichandran et al., Clearing the dead: Apoptotic cell sensing, recognition, engulfment, and digestion, Cold Spring Harbor Perspectives in Biology 5 (2013), a008748.

[5] E. Sackmann, F. Keber and D. Heinrich, Physics of cellular movements, Annual Review of Condensed Matter Physics 1 (2010), 257-276.

[6] K. Bambardekar, J.A. Dharmadhikari, T. Yamada et al., Shape anisotropy induces rotations in optically trapped red blood cells, Journal of Biomedical Optics 15 (2010), 041504.

[7] C. Zhu, T. Yago, J. Lou, V.I. Zarnitsyna and R.P. McEver, Mechanisms for flow-enhanced cell adhesion, Annals of Biomedical Engineering 36 (2008), 604-621.

[8] J.O. Barber, J.P. Alberding et al., Simulated two-dimensional red blood cell motion, deformation, and partitioning in microvessel bifurcations, Annals of Biomedical Engineering 36 (2008), 1690-1698.

[9] T.W. Secomb, B. Styp-Rekowska and A.R. Pries, Two-dimensional simulation of red blood cell deformation and lateral migration in microvessels, Annals of Biomedical Engineering 35 (2007), 755-765.

[10] A.R. Pries, K. Ley, M. Claassen and P. Gaehtgens, Red cell distribution at microvascular bifurcations, Microvascular Research 38 (1989), 81-101. 
[11] H.L. Goldsmith, Red cell motions and wall interactions in tube flow, Federation Proceedings 30 (1971), 1578-1590.

[12] K. Vahidkhah and N. Fatouraee, Numerical simulation of red blood cell behavior in a stenosed arteriole using the immersed boundary-lattice Boltzmann method, International Journal for Numerical Methods in Biomedical Engineering 28 (2012), 239-256.

[13] J.F. Zhang and P.C. Johnson and A.S. Popel, Red blood cell aggregation and dissociation in shear flows simulated by lattice Boltzmann method, Journal of Biomechanics 41 (2008), 47-55.

[14] J. Hasnedlová, M. Feistauer, J. Horáček et al., Numerical simulation of fluid-structure interaction of compressible flow and elastic structure, Computing 95 (2013), 343-361. 